This is an author-created, accepted version of the paper "Ground-based hyperspectral analysis of the urban nightscape" by R. Alamús et al. The published version of this paper can be found in ISPRS Journal of Photogrammetry and Remote Sensing, as doi:10.1016/j.isprsjprs.2016.12.004. (C 2016.

This manuscript version is made available under the CC-BY-NC-ND 4.0 license

http://creativecommons.org/licenses/by-nc-nd/4.0/

\title{
Ground-based hyperspectral analysis of the
}

\section{urban nightscape}

\author{
Ramon Alamús ${ }^{a}$, Salvador Baráb ${ }^{b},{ }^{*}$, Jordi Corbera ${ }^{a}$, Jaume Escofet ${ }^{c}$, Vicenç \\ Palà , Luca Pipia ${ }^{a}$, Anna Tardà \\ a Institut Cartogràfic i Geològic de Catalunya (ICGC), Parc de Montjuïc s/n, 08038 \\ Barcelona, Catalunya, Spain \\ b Área de Óptica, Departamento de Física Aplicada, Universidade de Santiago de \\ Compostela, Santiago de Compostela, Galicia, Spain \\ c Departament d'Òptica i Optometria, Universitat Politècnica de Catalunya, Terrassa, \\ Catalunya, Spain
}

\begin{abstract}
Airborne hyperspectral cameras provide the basic information to estimate the energy wasted skywards by outdoor lighting systems, as well as to locate and identify their sources. However, a complete characterization of the urban light pollution levels also requires evaluating these effects from the city dwellers standpoint, e.g. the energy waste associated to the excessive illuminance on walls and pavements, light trespass, or the luminance distributions causing potential glare, to mention but a few. On the other hand, the spectral irradiance at the entrance of the human eye is the primary input to evaluate the possible health effects associated with the exposure to artificial
\end{abstract}


light at night, according to the more recent models available in the literature. In this work we demonstrate the possibility of using a hyperspectral imager (routinely used in airborne campaigns) to measure the ground-level spectral radiance of the urban nightscape and to retrieve several magnitudes of interest for light pollution studies. We also present the preliminary results from a field campaign carried out in the downtown of Barcelona.

\section{Keywords}

Hyperspectral data; Urban; Outdoor lighting; Light pollution; Urban health; Urban planning;

* Corresponding author: Salvador Bará, Área de Óptica, Dept. Física Aplicada, Facultade de Óptica e Optometría, Universidade de Santiago de Compostela, 15782 Santiago de Compostela, Galicia, Spain.

E-mail: salva.bara@usc.es 


\section{Introduction}

Light pollution is an issue of growing interest for urban planners, city managers and environmental protection agencies. In its broadest sense, this term encompasses the undesired side-effects associated with the production and use of artificial light, especially at nighttime (Falchi et al., 2011; Bará, 2013, 2014). Excessive or misdirected light leads to unnecessary energy waste and increased greenhouse gas emissions (Gallaway et al., 2010; Kyba, 2014), and poses, according to recent findings, nonnegligible threats to the nocturnal environment (Hölker et al., 2010; Gaston et al., 2013, 2015) as well as potential health hazards (Cho et al., 2015; Haim and Zubidat, 2015; Stevens et al., 2013).

Making strategic decisions on outdoor lighting policy at local and regional levels requires an accurate knowledge of the actual light emissions, ideally with enough spatial and spectral resolution to allow the identification of individual light sources, their directional emission patterns and their detailed spectral composition (Elvidge et al., 2010).

Urban radiance data with moderate spatial resolution are currently available from several instruments on board of space platforms, such as the historical time series of the Operational Linescan System (OLS) of the U.S. Defense Meteorological Satellite Program (DMSP) (Cinzano and Elvidge, 2004; Elvidge et al., 2013; Yang et al., 2014), the Suomi-NPP VIIRS instrument Day-Night Band (DBN) (Miller et al., 2013), and the Earth images taken with commercial grade cameras from the International Space Station (ISS) (Castiglione et al., 2012). The DMSP and Suomi-NPP satellites, located in near polar orbits at altitudes close to $850 \mathrm{~km}$, provide whole Earth coverage with radiance detection limits of order $5 \times 10^{-10}$ and $2 \times 10^{-11} \mathrm{~W} \cdot \mathrm{cm}^{-2} \cdot \mathrm{sr}^{-1}$, and ground footprint sizes of $5 \mathrm{~km}$ and $742 \mathrm{~m}$, respectively. They give no spectrally resolved information, because the detection is performed in a single $0.5-0.9 \mu \mathrm{m}$ panchromatic band (Elvidge et al., 2013). NightPod-based ISS nigthtime imagery (Castiglione et al., 2012), acquired from an orbit at about $400 \mathrm{~km}$ altitude with $51.6^{\circ}$ inclination and variable footprint pixel size, is restricted in turn to the conventional Bayer matrix RGB bands. Despite this 
spectral limitation, satellite data are the primary source of information about urban wasted light at planetary scale (Cinzano et al. 2000, 2001; Cinzano and Elvidge, 2004; Sánchez de Miguel, 2014), correlate well with on-site flux measurements, and are useful tools for monitoring changes in upward light emissions after remodeling urban lighting systems (Estrada-García et al., 2015). The number of spaceborne instruments monitoring the city lights has been, however, comparatively very small until now (Belward and Skøien, 2015). Given the useful information they may provide and the relevance of the study of the anthropogenic emissions of light It is highly desirable that new satellite programs, ideally with nighttime multispectral capabilities, be planned in the near future.

Considerably better spatial and spectral resolution can be achieved with airborne hyperspectral imaging spectrometers, at the expense of a smaller area coverage. Hyperspectral imaging, that has found many applications in Earth imagery (see, e.g., Aasen et al, 2015; Clark et al., 2016) including urban areas (Demarchi et al, 2014; Kotthaus et al, 2014), has also been succesfully applied to the study of nighttime artificial lights (Barducci et al., 2003, 2003b, 2006; Kruse and Elvidge, 2011). Airborne hyperspectral measurements combined with photogrammetric imagery allow to obtain reliable estimates of the upward luminance from urban areas with spatial resolutions well below one meter, as we have shown in previous works (Pipia et al., 2014; Corbera et al. 2015).

The overall radiant flux emitted towards the upper hemisphere by urban areas is a measure of the degree of lighting energy waste and is the leading cause of increased skyglow. This flux, however, is only part of the whole light pollution picture. Several detrimental effects of light pollution are essentially ground-level phenomena. They include, among others, light intrusion, dissability and discomfort glare, light clutter, and the diverse photobiological effects of light at night. To evaluate the severity of these effects one needs to know the spectral radiance of the urban nightscape, as seen from the city dwellers standpoint. This radiance distribution allows the assessment of glare and light cluttering. It is also instrumental for computing the spectral irradiance in a plane tangent to the human corneal vertex for arbitrary gaze directions, which is 
the primary input for evaluating the physiological effects of light at night by means of suitable phototransduction models (CIE, 2015; Rea et al. 2005, 2010, 2012). The vertical irradiance on window panes allows, in turn, to quantify the severity of light trespass effects.

As in other areas of remote sensing (Chen et al, 2016), a comprehensive assessment of the overall levels of light pollution can only be achieved if the airborne and satellite data are complemented with ground based measurements acquired from within the town. In this work we describe the adaptation and operation of a hyperspectral imaging sensor routinely used for airborne surveys to acquire these additional datasets from the city streets. Hyperspectral light pollution measurements require dealing with spatially uneven, high dynamic range radiance distributions, and keeping the noise propagation within admissible levels. In section 2 we describe the hyperspectral measurement system. The data reduction process implemented to get the desired magnitudes is summarized in section 3. The results of a proof-of-concept measurement campaign carried out in the city of Barcelona are reported in section 4. Discussion and conclusions are finally drawn in sections 5 and 6, respectively.

\section{Materials}

\subsection{Site selection}

The field campaign was carried out at the city of Barcelona ( 3 million inh.), capital of Catalonia, in the period around the new Moon in February 19th to 20th, 2015. Its public outdoor lighting is mainly based on high pressure sodium vapor and metal halide lamps, with an increasing presence of phosphor-coated white Light Emitting Diode (LED) streetlights and self-luminous billboards. Several downtown areas were selected for measurements, including Plaça d'Espanya (site 1) and Jardinets de Gràcia (site 2), shown in Fig. 1, because they are zones presenting a high density of pedestrian traffic, main street intersections, and a representative sample of the lighting technologies used in the city. 

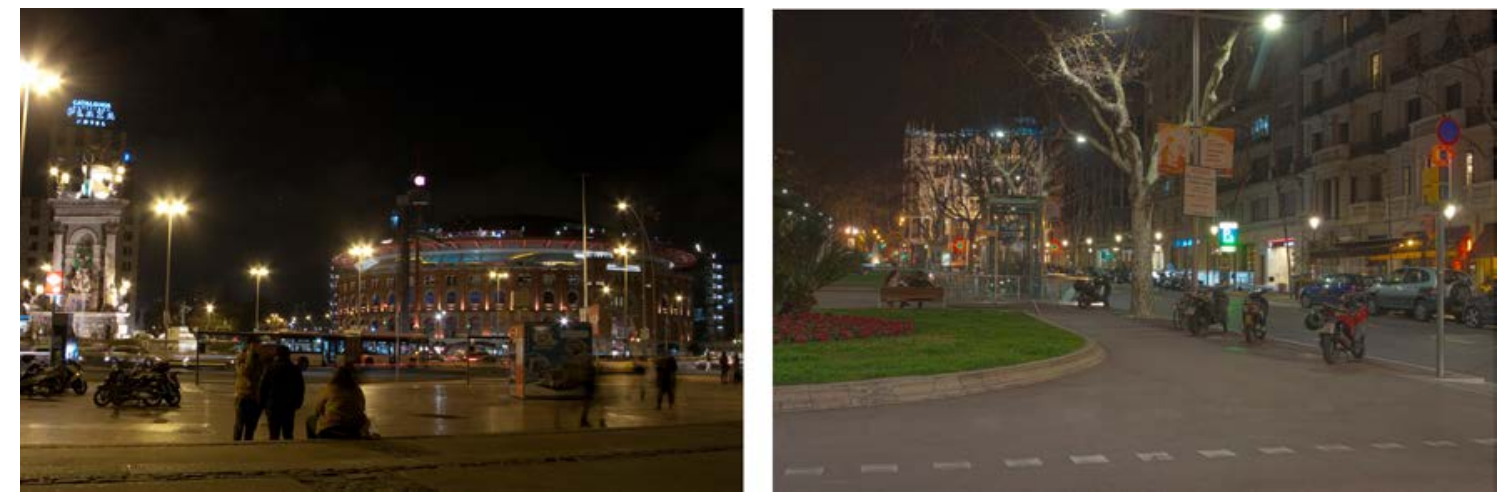

Fig. 1. Two measurement sites in downtown Barcelona. Left: Plaça d'Espanya. Right: Jardinets de Gràcia.

\subsection{Hyperspectral camera and mount}

Hyperspectral data cubes were acquired with an AISA Eagle II sensor assembled on a HEQ5-Pro microprocessor-controlled astronomic equatorial mount. The mount declination axis was pointed vertically, so that the rotation around this axis allowed the camera to work in an azimuthal push-broom configuration. A lens of $f=18.5 \mathrm{~mm}$ imaged the urban nightscape onto the camera sensor, providing a vertical field of view of $37.7^{\circ}$. The 1024 native spatial pixels acquired in each of the spectral bands were binned $2 x$, giving an effective instantaneous field of view (iFOV) in the vertical direction of 4.4 minutes of arc. A total of 6990 azimutal samples were acquired in each complete rotation of the mount, providing an horizontal iFOV of 3.1 minutes of arc. A spectral binning $4 \mathrm{x}$ provided 128 equally-distributed spectral channels from $390 \mathrm{~nm}$ to $1000 \mathrm{~nm}$ with $4.8 \mathrm{~nm}$ resolution.

Typical exposure times lie in the range 18 - $164 \mathrm{~ms}$. The exposure times were chosen to fulfill geometric as well as radiometric criteria. From a geometric standpoint the exposure times were selected among those that provided an horizontal iFOV of the same order of magnitude than the vertical iFOV of the sensor, in order to avoid too large differences, and to obtain pixels as close to square as possible. Notice that the horizontal iFOV depends on the mount rotation speed and the sensor integration time, and that the available rotation speeds were limited to the discrete set of values provided by the commercial mount. The radiometric criterium is related to getting the 
optimal exposure of the scene, that is, trying to get the minimum number of saturated pixels and the maximum signal in dark areas. The flicker frequency of the sources shall also be taken into account: most urban light sources flicker at twice the $A C$ mains frequency ( $50 \mathrm{~Hz}$ in Barcelona), with a modulation amplitude that may take a broad range of values, depending on the lamp technology, and may in many cases be significant. If exposure times are smaller than the flicker period $(10 \mathrm{~ms})$ some bias may appear in the detected radiance of individual sources. The influence of the flicker in the aggregate radiometric balance of the whole urban scene is attenuated due to the fact that urban light sources are often alternated in a 3-phase electrical system scheme. In our case the exposure times were always above this basic period, and close to integer multiples of it. The optimum settings to be used in each urban site strongly depended on the particular features of the illuminated nightscape, and were determined on a case-by-case basis by means of on-field analysis of trial scans. Raw images were stored with 12-bit effective depth for subsequent post processing. A typical pseudo-RGB panoramic image of the Jardinets de Gràcia site is displayed in Figure 2.

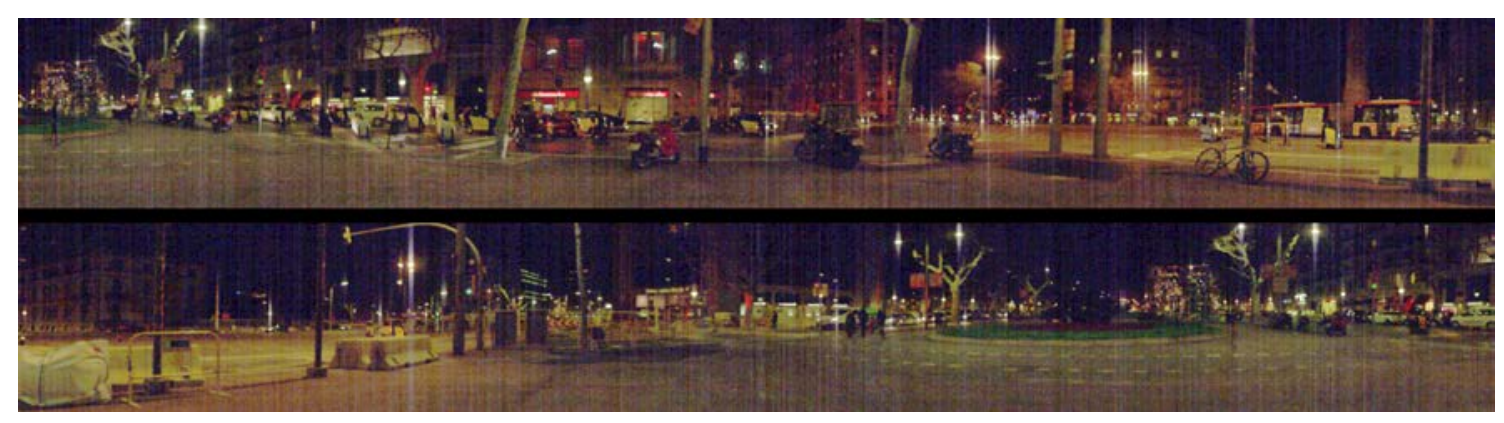

Fig. 2. Panoramic $360^{\circ}$ pseudo-RGB image (bands $625.61,555.05$ and $427.14 \mathrm{~nm}$, respectively RGB) obtained from the hyperspectral cube taken at Jardinets de Gràcia. Notice that (i) in order to provide a better visualization the image has been enhanced and (ii) the end part of the image -lower right- overlaps the beginning of the image -upper left.

\section{Methods}

In this section it is described on the one hand the theoretical frame of the work, 
including the products derived from the hyperspectral images, and, on the other hand, some image processing methods to deal with several image artifacts inherent to night images.

\subsection{Output products}

The spectral radiance of the nocturnal environment is the primary input for computing a set of specific magnitudes relevant for light pollution studies. Radiometric and photometric magnitudes can be easily computed from it. For instance, from the basic definitions of radiometry (Schreuder, 2008), it follows that the spectral irradiance $E\left(\lambda ; \mathbf{x}_{\mathbf{0}}, \boldsymbol{\alpha}_{\mathbf{0}}\right)$ at any given point $\mathbf{x}_{\mathbf{0}}$ located in an arbitrarily oriented surface defined by its normal vector $\boldsymbol{\alpha}_{\mathbf{0}}$ can be determined as (McCluney, 2014):

$$
E\left(\lambda ; \mathbf{x}_{\mathbf{0}}, \boldsymbol{\alpha}_{\mathbf{0}}\right)=\iint_{\Omega} L\left(\lambda ; \mathbf{x}_{\mathbf{0}}, \boldsymbol{\alpha}\right) \cos \left(\boldsymbol{\alpha}, \boldsymbol{\alpha}_{\mathbf{0}}\right) d \Omega(\boldsymbol{\alpha}),
$$

where $\boldsymbol{\alpha}$ denotes the position vector of the points of the environment in a reference frame centered in $\mathbf{x}_{\mathbf{0}}, L\left(\lambda ; \mathbf{x}_{\mathbf{0}}, \boldsymbol{\alpha}\right)$ is the spectral radiance reaching $\mathbf{x}_{\mathbf{0}}$ from the direction of $\boldsymbol{\alpha}, d \Omega(\boldsymbol{\alpha})$ is the elementary solid angle around this direction, and the solid angle integral is extended to $\Omega$, the hemispheric field-of-view whose pole lies in the direction of $\boldsymbol{\alpha}_{\mathbf{0}}$. The notation $\cos \left(\boldsymbol{\alpha}, \boldsymbol{\alpha}_{\mathbf{0}}\right)$ stands for the cosine of the planar angle formed by the vectors $\boldsymbol{\alpha}$ and $\boldsymbol{\alpha}_{\mathbf{0}}$, that is, by the direction of the point $\boldsymbol{\alpha}$ of the environment and by the normal to the surface, and is given by $\cos \left(\boldsymbol{\alpha}, \boldsymbol{\alpha}_{\mathbf{0}}\right)=\boldsymbol{\alpha} \cdot \boldsymbol{\alpha}_{\mathbf{0}} /\left(\left|\boldsymbol{\alpha} \| \boldsymbol{\alpha}_{\mathbf{0}}\right|\right)$, where the dot indicates scalar product and || stands for modulus. The photometric magnitudes are computed weighting the spectral radiometric ones by the corresponding visual efficiency functions in the photopic, mesopic or scotopic ranges (CIE, 2010).

In order to verify the compliance with lighting standards and the regulations aiming to ensure an adequate visual performance without unnecessary energy waste, the usual magnitudes of choice are the luminance of the sources, walls, signs and 
pavements, as well as the horizontal and vertical illuminances at specified places and orientations.

Non-visual light pollution interactions are assessed using different models, depending on the effects under study. Although there are still considerable uncertainties in this field, the basic mechanisms of the interaction of artificial light at night with the human physiology are progressively being unveiled (see the review in Bonmati-Carrion et al., 2014). A comprehensive model describing the effects of the nocturnal exposure to light on the production of the hormone melatonin (MLT) has been proposed by Rea et al $(2005,2010,2012)$. This model provides quantitative predictions of the percentage of acute MLT suppression in blood (CS), under some definite experimental lighting conditions. In order to characterize the input to the circadian regulation system a new magnitude, circadian light $\left(C L_{A}\right)$, has been defined in terms of the spectral irradiance incident on a plane tangent to the observer's corneal vertex, and of the known physiological reponse functions of the visual $(S, M$ and $L$ cones, and rods) and non-visual (intrinsically photosensitive retinal ganglion cells, ipRGC) human photoreceptors (Rea, 2010). A related but different way of characterizing the photic input to the human circadian system, without explicitly providing the expected outputs, has been recently proposed by Lucas et al. (2014), and complemented with some additional CIE recommendations in order to accomodate it to the standard guidance on the use of SI units (CIE, 2015). In this model, the inputs $J_{\alpha}$ to the five basic human photoreceptors are computed as weighted integrals of the spectral irradiance on the cornea, $E(\lambda)$, as

$$
J_{\alpha}=K_{\alpha} \int w_{\alpha}(\lambda) E(\lambda) \mathrm{d} \lambda
$$

where the subindex $\alpha=1, \ldots, 5$, labels each of the basic photoreceptors, $w_{\alpha}(\lambda)$ are their spectral weighting functions, and the $K_{\alpha}$ are suitable normalization constants (CIE, 2015; Lucas et al., 2014). Figure 3 shows the weighting functions correspoding to the $S$ (cyanopic), M (chloropic) and L (erythropic) cones, the rods (rhodopic) and the ipRGC 
(melanopic), normalized following the CIE recommendations.

In the next section we show how to compute the values of several of these magnitudes from the appropriate hyperspectral datasets. In particular, we concentrate on the photopic and scotopic luminance of the environment, relevant for vision and energy management, and on the inputs to the five basic photoreceptors, relevant for human health issues. An estimation of the physiological output, in terms of the percentage of acute MLT suppression, is also calculated from the hyperspectral image cube data.

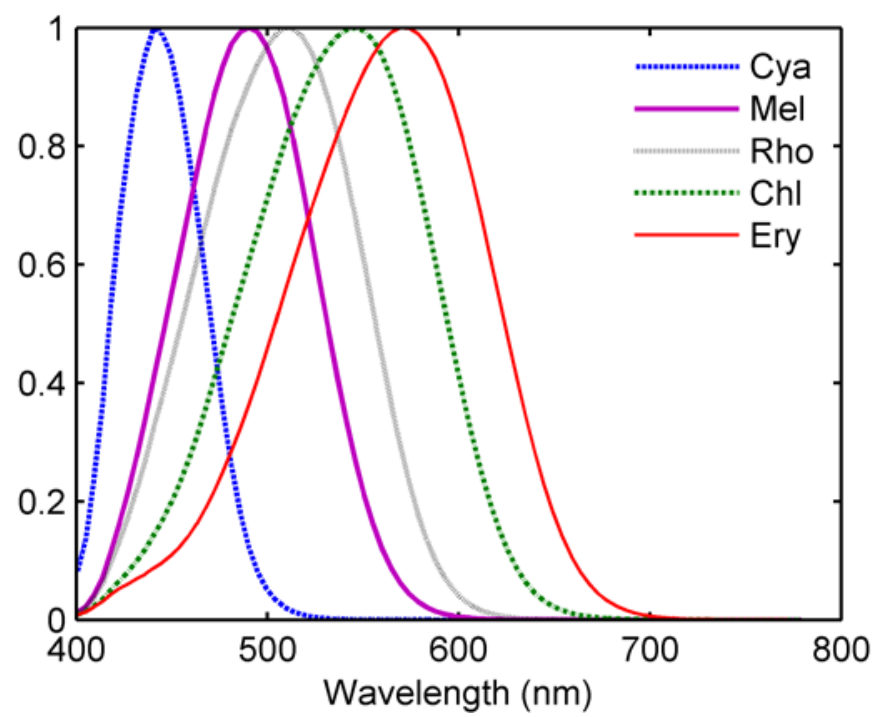

Fig. 3. CIE-normalized $w_{\alpha}(\lambda)$ spectral weighting functions for the cyanopic, melanopic, rhodopic, chloropic and erythropic channels (color online).

Being able to identify the different types of light sources is a necessary condition for evaluating their respective contributions to the overall corneal irradiance and for making informed decissions about the convenience of undertaking lamp replacement programs. Although in principle this could be made using information from the installation records of the corresponding administrative city lighting services, hyperspectral imagery offers a more direct and dependable way of identifying the lamps present at the time of the campaigns in the analyzed nighstcape, by comparing their spectral signatures against the templates available in existing databases (Elvidge at al., 2010). Since present streetlights are chosen among a relatively reduced number of light production technologies, each one with a characteristic spectral signature, 
source identification can generally be done with a high level of reliability.

\subsection{Preprocessing}

The exposure settings try to balance the sensitivity of the sensor against the large dynamic range of the night scene: In a typical single scene we are dealing with almost completely dark areas which lie at the dark current level present in the raw image (1-2 DN), and extremely bright small regions (as e.g, some lamps along the sensor line of sight) that reach the saturation level at 4095 DNs in the raw image. Because of that, raw hyperspectral night images very often show regions where the main contribution comes just from noise and pointlike ones with overexposed (saturated) pixels.

The noise level measured in dark or unexposed areas has small variations from line to line scanned by the pushbroom sensor. Although these differences are small (a few DN counts) they were compensated in the preprocessing step. We took advantage of the fact that every raw image contains a set of lines acquired with the shutter closed, with the goal of removing the mean dark current noise. We used the average value of these readings to set the background noise at the same level in all lines.

\subsection{Dealing with saturated regions.}

As commented above, a characteristic feature of the urban nightscape is the large dynamic range of its highly uneven radiance distribution. The direct streetlight radiance is often greater, by several magnitude orders, than the one from the diffuse reflections at building walls or pavements. Hence, if the exposure time is set to record with enough signal-to-noise ratio (SNR) the less illuminated surfaces, the pixels where the light emitting lamps are imaged may get saturated at least in some of their spectral channels. An effective way of dealing with this problem is to make repeated scans of the urban nightscape with different exposure times, and to combine the resulting hyperspectral image cubes in a way similar to the one used in conventional High Dynamic Range imaging (HDRi) (Mann and Picard, 1995; Cai, 2013). However, if the 
number of overexposed pixels is small and they have at least a subset of unsaturated wavelength channels, a simple but reliable correction procedure can be applied to the partially saturated single scans. It takes advantage from the fact that the pixels adjacent to the saturated ones correspond in most cases to the same light source, and share therefore the same spectral signature. The saturated spectral channels can then be reconstructed from the information contained in the unsaturated neighboring pixels.

This correction procedure has the following steps: the spatial pixels that are saturated are detected in the original 12-bit uncalibrated raw image, and a saturation mask is generated. A spatial pixel is labeled as saturated if at least one of its spectral channels reaches the saturation level of 4095 DN (see Fig. 4, left). The unsaturated pixels that surround each saturated region are located by subtracting this mask from a dilated version of itself. Subsequently, the sum over wavelengths of the spectral signature of each unsaturated pixel is normalized to unity and a spectral template defined by the average of the normalized spectral signatures around each saturated region is computed (Fig. 4 center). The spectral signature of each saturated pixel is reconstructed, in all spectral bands with values higher than $3800 \mathrm{DN}$, by scaling this template by a multiplicative factor that is determined from the actual values of the spectral channels that were not saturated. In that way (Fig. 4, right) we obtain a corrected pixel spectrum and a raw image hypercube without saturations. Note that after performing this step the bit depth of the resulting image may be greater than the original one. As a matter of fact, saturated 12-bit images may become 16-bit or even larger after correction. Finally, the corrected raw image is radiometrically calibrated following the camera manufacturer protocol and procedures. It was performed using the version of the manufacturer software CaliGeoPRO $\vee 2.2 .4$. More details can be found in Babey and Soffer (1992), where a calibration protocol similar to the one used with the AISA Eagle II is described. 

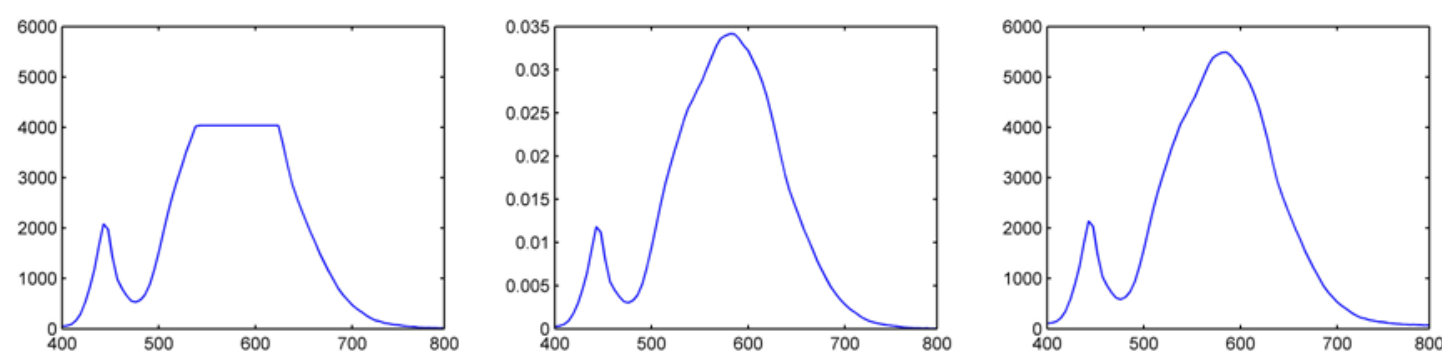

Fig. 4. Left: spectrum of a raw image saturated pixel (saturation level at $4095 \mathrm{DN}$ ); center: normalized spectrum of the unsaturated pixels of its neighborhood (dimensionless); and right: retrieved/reconstructed spectrum of the saturated pixel. Vertical axis: pixel value, in DN. Horizontal axis: wavelength in $\mathrm{nm}$.

Note that the feasibility of the proposed correction procedure is contingent on the availability of neighboring pixels having the same spectral signature as the saturated ones. In most nightscape images this condition can be met if the number of saturated pixels is kept at a minimum, such that at least one spatial pixel within the image of each source is unsaturated, as it was our case. The number of saturated pixels in our images was small: it amounted to $0.01 \%$ of the total number of pixels of the scene, in the most affected spectral band (569 nm). One or several of the remaining bands were saturated in less than $0.009 \%$ pixels. Take into account that the actual number of saturated bands may differ from one saturated pixel to another. No saturation was recorded below $420 \mathrm{~nm}$ or above $890 \mathrm{~nm}$. No pixel experienced saturation in all wavelengths of the spectrum.

Glare haloes can be observed around the most intense light sources. The main effect of the glare produced by reflections in the internal optical elements of the hyperspectral camera is the redistribution of part of the energy of the source across adjacent pixels of the scene. Although not used in this work, some glare pixels could be an alternate source of information for an approximate correction of highly saturated pixels if the haloes outstand over a much weaker background, since in that case the main features of the original source spectrum are reasonably preserved. Note, however, that this will not be the case if the saturated source is viewed against an extended intense light background as, e.g., a high luminance LED billboard. Light sources may also show some degree of non-uniformity and non-isotropy in their 
radiance patterns. In those cases the spectra of adjacent geometrical points of the source as seen from the camera could differ to a bigger or lesser extent, potentially compromising the quality of the saturation correction. In typical nightscape images, however, most urban light sources are mapped to a small number of pixels, averaging that way their possible spatial non-uniformities. The possible lack of isotropy of the lamp emission from adjacent pixels of the image is not expected to have significant effects, due to the small angular iFOV of the sensor. Before performing the saturation correction it is always advisable to check for the coincidence of the spectral signature of the saturated pixels, in their unsaturated spectral region, and the adjacent ones, within the same wavelength region (Fig. 4).

\subsection{Reducing the noise propagation}

In wide regions of nocturnal hyperspectral images the actual signal is extremely small and the main contribution comes from noise, especially in the long-wavelength end of the spectrum. In order to avoid an excessive bias when computing integrated spectral magnitudes (e.g. overall irradiance on surfaces), those pixels whose values were below a threshold noise level were set to zero. The threshold was established at three standard deviations above the average number of counts registered in the dark lines, which have been acquired with the shutter closed.

\section{Results}

The outcomes presented in this section correspond to the Jardinets de Gràcia site, and are based on the data taken in the night of February 19th to 20th, 2015. This date was chosen to minimize the contribution of moonlight to the nigtscape radiance. The new Moon occured at 00:49h of Feb 19th (local time CET=UTC+1). Sunset took place at 18:29 of Feb 19th and the Moon was below the horizon from 19:25h of this day until 08:20h of Feb 20th. The measurements were taken in the first part of the night, from 20:35 until midnight. 


\subsection{Luminance of the urban nightscape}

The luminance of the urban nightscape $\left(\right.$ in $\mathrm{cd} / \mathrm{m}^{2}$ ) for a photopically adapted eye was computed as the integral of the spectral radiance weighted by the $\mathrm{CIE} 2^{\circ}$ photopic spectral luminous efficiency function for foveal vision, $V_{\lambda}$ (Stockman et al., 2008) multiplied by the standard luminous efficacy constant $K_{\text {phot }}=683 \mathrm{Im} / \mathrm{W}$. The luminance for a scotopically adapted eye was computed in an analogous way, using the scotopic spectral luminous efficiency function $V_{\lambda}^{\prime}$ (CIE, 1951), with the efficacy constant for scotopic adaptation $K_{\text {scot }}=1700 \mathrm{Im} / \mathrm{W}$. The results are shown in Figure 5 . The average photopic luminance of the scene is $4.18 \mathrm{~cd} / \mathrm{m}^{2}$, and the scotopic one is $3.86 \mathrm{~cd} / \mathrm{m}^{2}$. The scotopic-to-photopic ratio (S/P), computed for each individual pixel and averaged over the whole scene, is 0.22 . Note that the local brightness, as well as the contrast of the nightscape, may be different for photopic- and scotopic-adapted eyes. The state of adaptation of the observer may hence determine the ability of perceiving some features of the city nightscape.
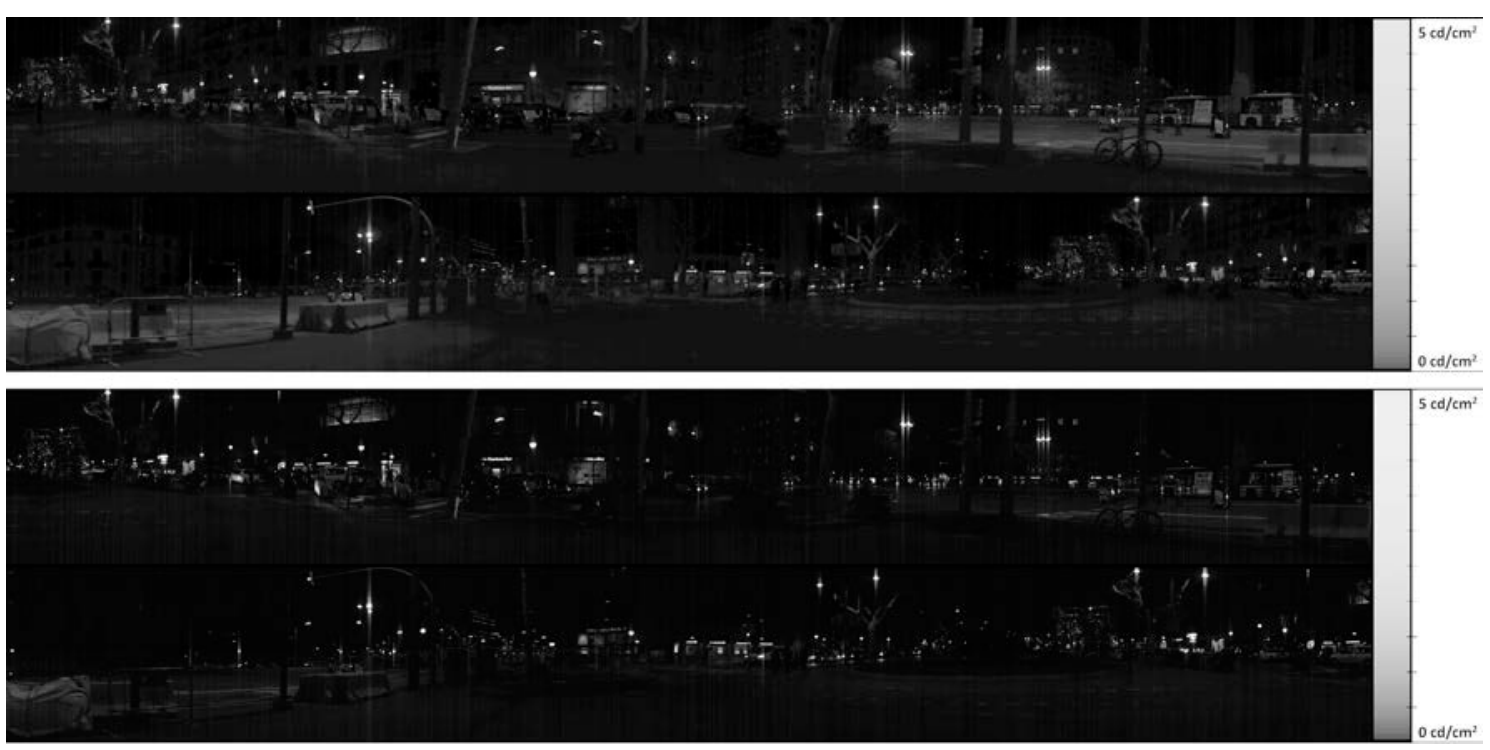

Fig. 5. Photopic luminance (top), and scotopic luminance (bottom), at Jardinets de Gràcia. The scale bar range is $0-5 \mathrm{~cd} / \mathrm{cm}^{2}\left(1 \mathrm{~cd} / \mathrm{cm}^{2}=10^{4} \mathrm{~cd} / \mathrm{m}^{2}\right)$ 

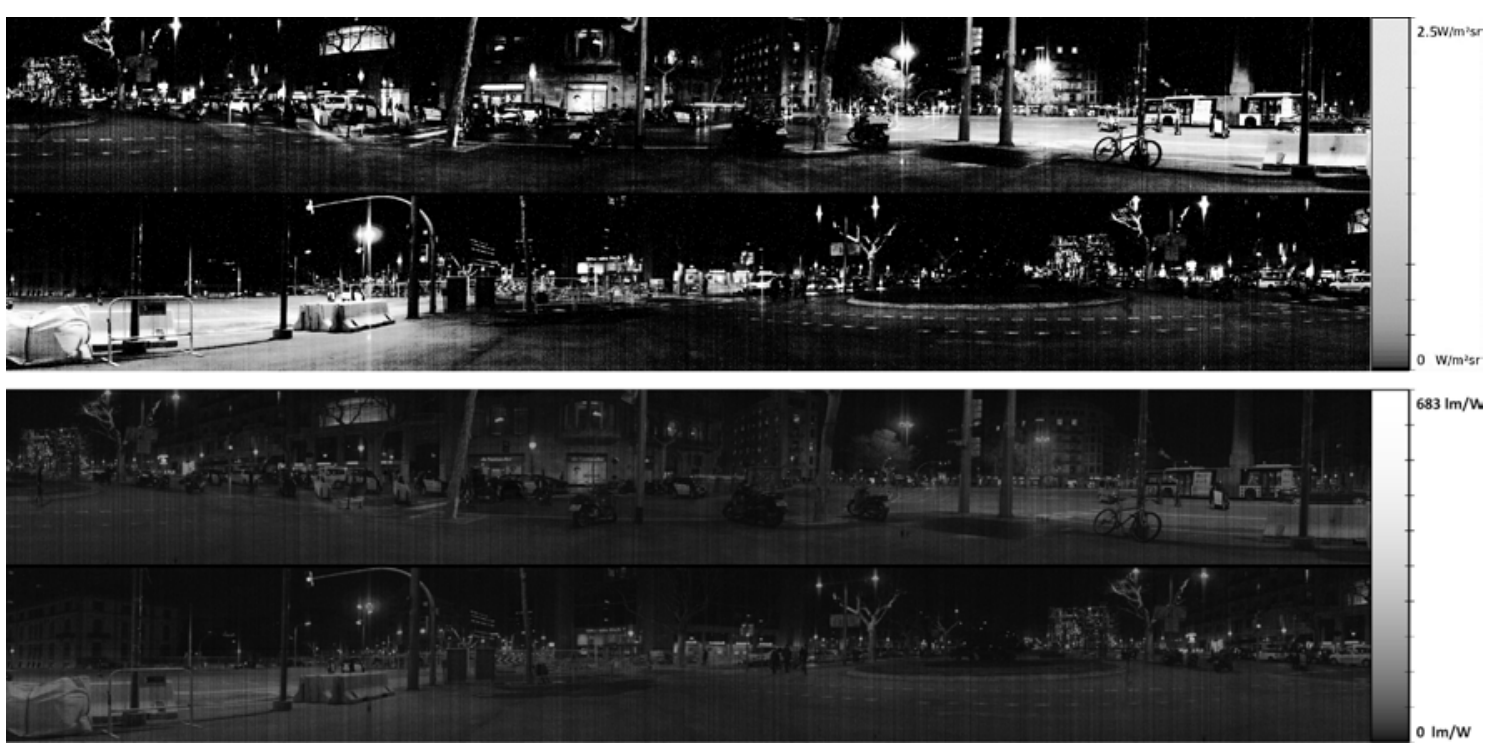

Fig. 6. Top: Integrated radiance $\left(\mathrm{W} \cdot \mathrm{m}^{-2} \cdot \mathrm{sr}^{-1}\right)$, and bottom: photopic luminous efficacy of radiation (LER) for the nightscape shown in Figure 5.

The overall radiance of the visual field, in $\mathrm{Wm}^{-2} \mathrm{sr}^{-1}$, is displayed in Fig. 6 (top). The ratio of the photopic luminance to the radiance gives us the photopic luminous efficacy of the radiation (LER) that comes to the observer from each point of the visual field, in $\mathrm{Im} / \mathrm{W}$ (Fig. 6 , bottom). This ratio quantifies the ability of a given beam of radiation to elicit the visual response in humans adapted to photopic light levels. The LER is in general different for the radiation arriving from each direction of the environment, since it has different spectral compositions depending on the location and type of the sources and on the spectral reflectance of the buildings, pavements, and vegetation present in the urban landscape surrounding the observer. The theoretical maximum attainable photopic LER value is $683 \mathrm{Im} / \mathrm{W}$, corresponding to a strictly monochromatic green beam of wavelength $555 \mathrm{~nm}$.

\subsection{Source identification}

The spectral signature of the pixels corresponding to the street lamps allow their easy identification, by comparison with the spectra obtained in the laboratory (Elvidge, 2010). Figure 7 shows three examples of different lamp spectra measured in the image. 

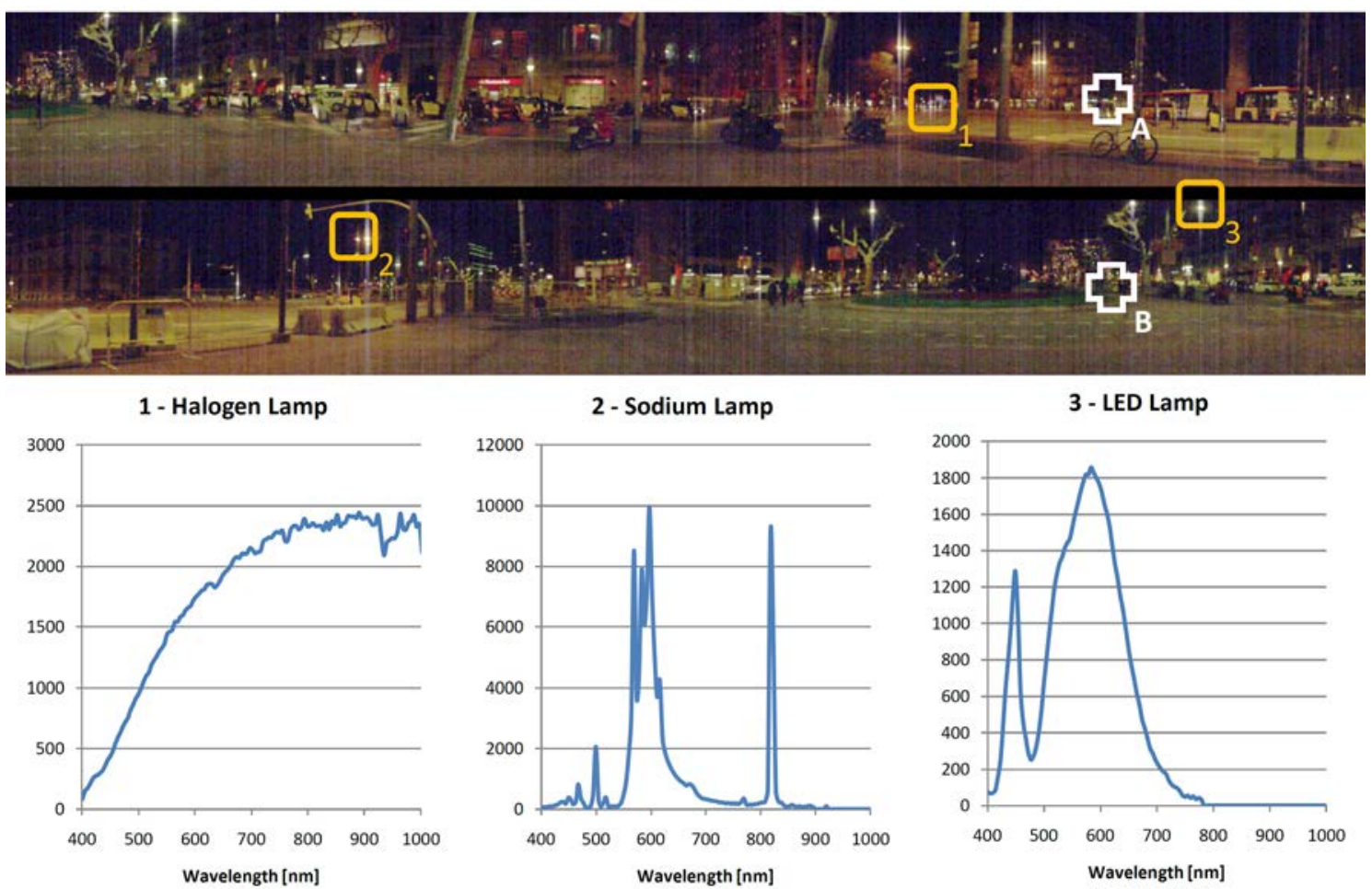

Fig. 7. Three streetlight spectra that can be observed in the scene at site 2 . From top left to bottom right: 1) an halogen car light, 2) a high pressure sodium lamp and 3) a LED Lamp. Spectral radiances in $\mu \mathrm{W} \cdot \mathrm{cm}^{-2} \cdot \mathrm{sr}^{-1}$. The centers of the crosses label two selected fixation points, $A$ (azimuth $245.40^{\circ}$ ) and $B$ (azimuth $38.75^{\circ}$ ), of an observer gazing horizontally to the urban nightscape (see Section 4.3 and Fig. 8)

\subsection{Irradiances on canonical planes}

Current standards on street illumination and regulations seeking to avoid light trespass (that is, the intrusion of light in zones that shall not be lighted, as vegetation areas, private homes, etc), establish lower and/or upper limits on the illuminance permissible on horizontal planes (e.g., pavements) and vertical ones (e.g., walls and windows). On the other hand, the spectral irradiance in a plane tangent to the cornea of the human eye is the basic input to assess the circadian effects of light. The hyperspectral scan of the urban nightscape provides useful information to evaluate these radiometric and photometric magnitudes.

As an example of application of hyperspectral imaging in urban sites we have used 
the measured radiances to compute, using Eq. (1), the spectral irradiance at the vertical plane tangent to the eye cornea of an observer gazing horizontally along all azimuths in the range $\left(0^{\circ}-360^{\circ}\right)$. Figure 8 shows two typical corneal spectral irradiance patterns obtained at site 2 . The full line corresponds to the irradiance at the cornea when the observer is looking at the point of the nightscape located at the center of the cross A in Fig. 7, and the dotted line corresponds to the same observer looking at the point situated in the center of the cross B in the same figure. Note that these spectral distributions correspond to corneal irradiances, not to the radiance of the points at which the observer is fixating her or his gaze. The corneal irradiance is built up, according to Eq. (1), from the contributions of the radiance of all points of the hemisphere located in front of the observer, whose pole is in each case the corresponding visual fixation point. The irradiance pattern shown with a full line is strongly determined by the intense emissions of neighboring high pressure sodium vapor lamps, which make most of the streelights in this hemisphere of the scene. The dotted pattern is a combination of much weaker sodium signals with typical LED emissions, due to the white LED sources installed in the walkway at the opposite side of the scene.

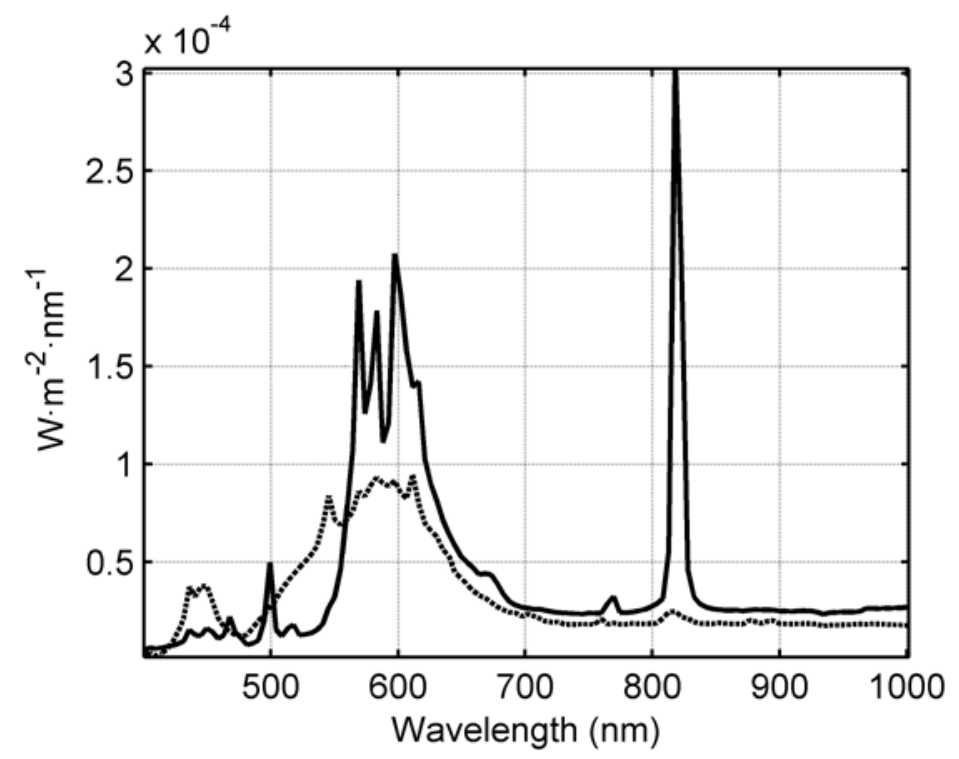

Fig. 8. Spectral irradiances at a plane tangent to the observer's cornea for the two gaze directions indicated in Fig. 7 by the centers of the crosses A and B. Full line: A (azimuth $245.40^{\circ}$ ) dotted line: B (azimuth $38.75^{\circ}$ ). See text for details. 


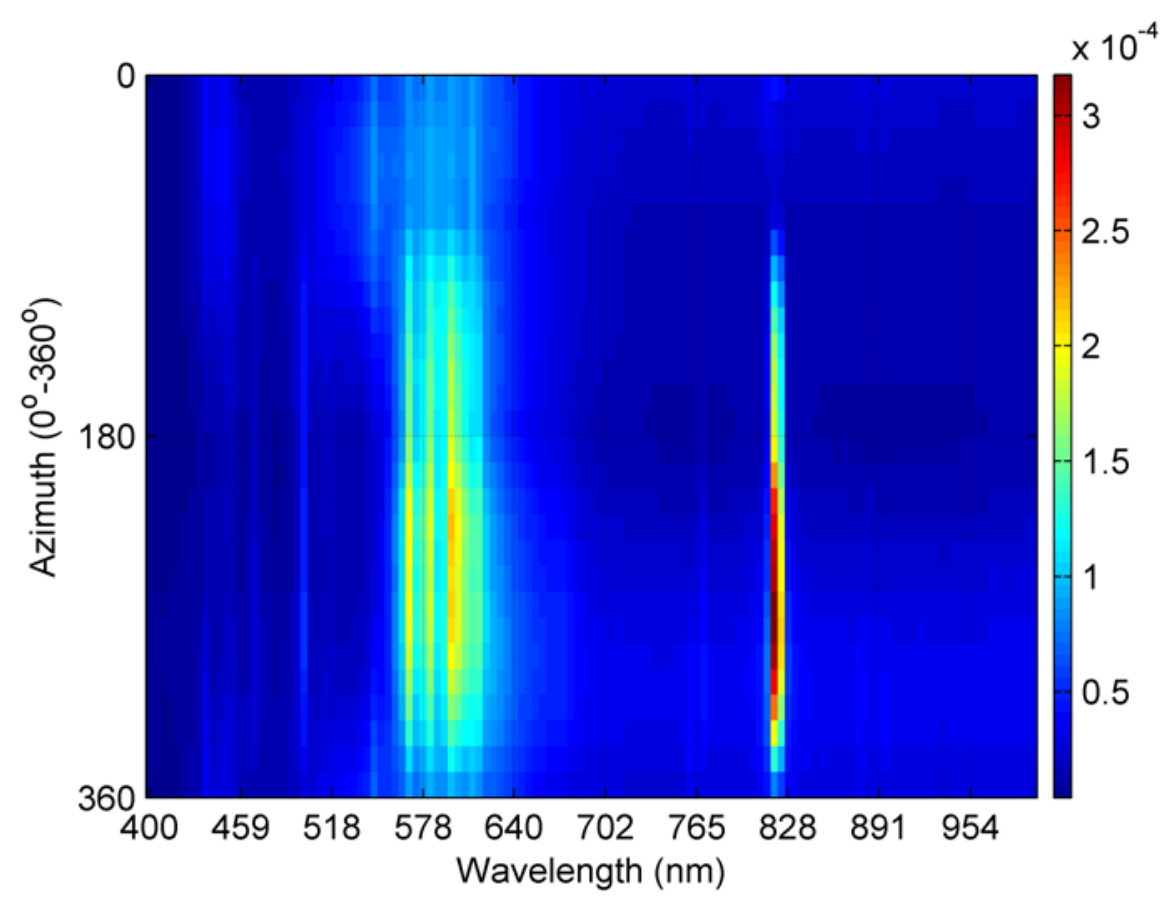

Fig. 9. Spectral irradiances $\left(\mathrm{W} \cdot \mathrm{m}^{-2} \cdot \mathrm{nm}^{-1}\right)$ at a plane tangent to the observer's cornea at site 2 gazing horizontally for all azimuths $\left(0^{\circ}-360^{\circ}\right)$.

Fig. 9 displays in matrix form the spectra of the overall irradiance distributions incident on the cornea of the eye at site 2 (wavelengths in the horizontal axis), as the eye scans the whole landscape, gazing horizontally (azimuths of gaze in the vertical axis). The two curves shown in Fig 8 correspond to horizontal slices of this figure, namely those corresponding to the azimuths $245.40^{\circ}$ (full line, A) and $38.75^{\circ}$ (dotted line, B). From this figure it can be assessed at a glance the shape of these spectra, and their variability across the directions of gaze. The typical high pressure sodium vapor lines (including the prominent one at $820 \mathrm{~nm}$ ) are apparent and dominate the spectral patterns for most of the sight directions.

From the corneal spectral irradiances it is possible to compute the inputs to the circadian regulation system, using Eq. 2 in the terms established by CIE (2015). Fig. 10 shows the resulting photoreceptor inputs, in units $\mathrm{W} / \mathrm{m}^{2}$. The relative weight of the five photoreceptoral inputs for each azimuth of gaze is determined by the particular mix of sources present in each case in the hemisphere in front of the observer. 


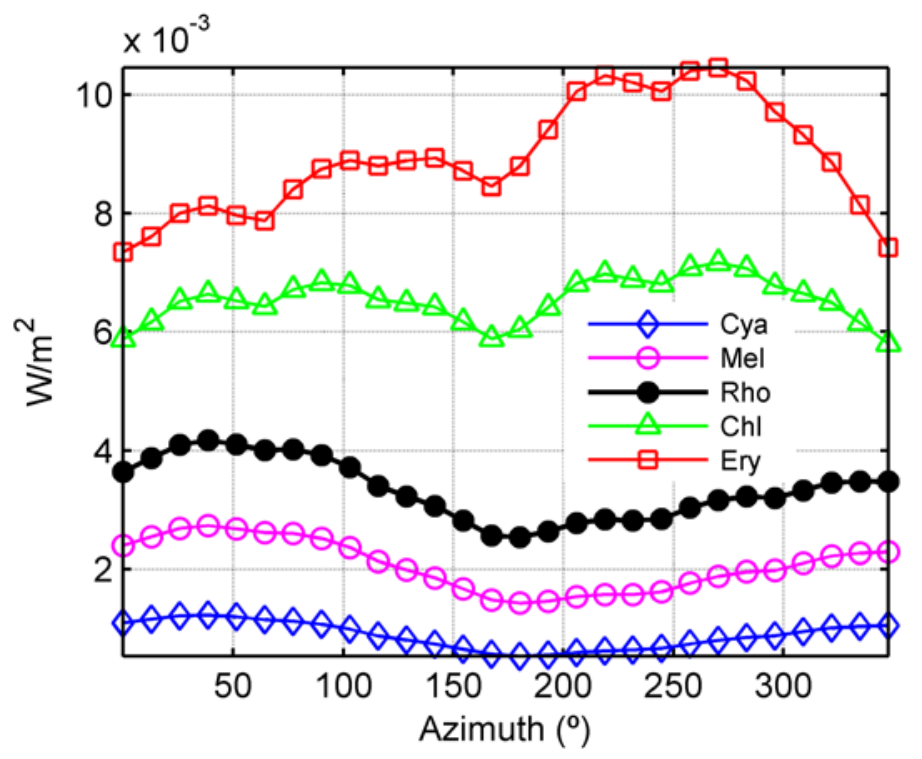

Fig. 10. Radiometric corneal inputs $\left(\mathrm{W} / \mathrm{m}^{2}\right)$ of the five basic human retinal photoreceptors for an observer located at site 2, gazing horizontally, for all azimuths $\left(0^{\circ}-360^{\circ}\right)$ : S-cones (diamonds), ipRGC (open circles), rods (full circles), M-cones (triangles) and L-cones (squares).

The photopic and scotopic luminances can be similarly evaluated by weighting the spectral radiance with the CIE luminous efficiency functions for the photopic $\left(V_{\lambda}\right)$ and scotopic $\left(V^{\prime}{ }_{\lambda}\right)$ ranges. Complementarily, the hyperspectral data cube allows to evaluate the radiance of the nightscape in each of the photoreceptor bands, helping us to identify particular sources contributing to the final input values. The photopic and scotopic nightscapes are displayed in Fig. 4 above. The outlook of the urban night environment in the five CIE photoreceptoral input bands is shown in Fig. 10.

According to Rea's et al. model (Rea et al. 2005, 2010, 2012), the corneal irradiances at this site are rather low to produce any significant circadian disruption. At the measured levels of illumination, and taking into account the particular spectral composition of the light reaching the observer eyes, the expected values of acute melatonin suppression after one-hour exposure to these urban light sources fall below the $1 \%$ level for any horizontal line of sight, an amount which is smaller than the nominal uncertainty of the Rea's et al. model. 

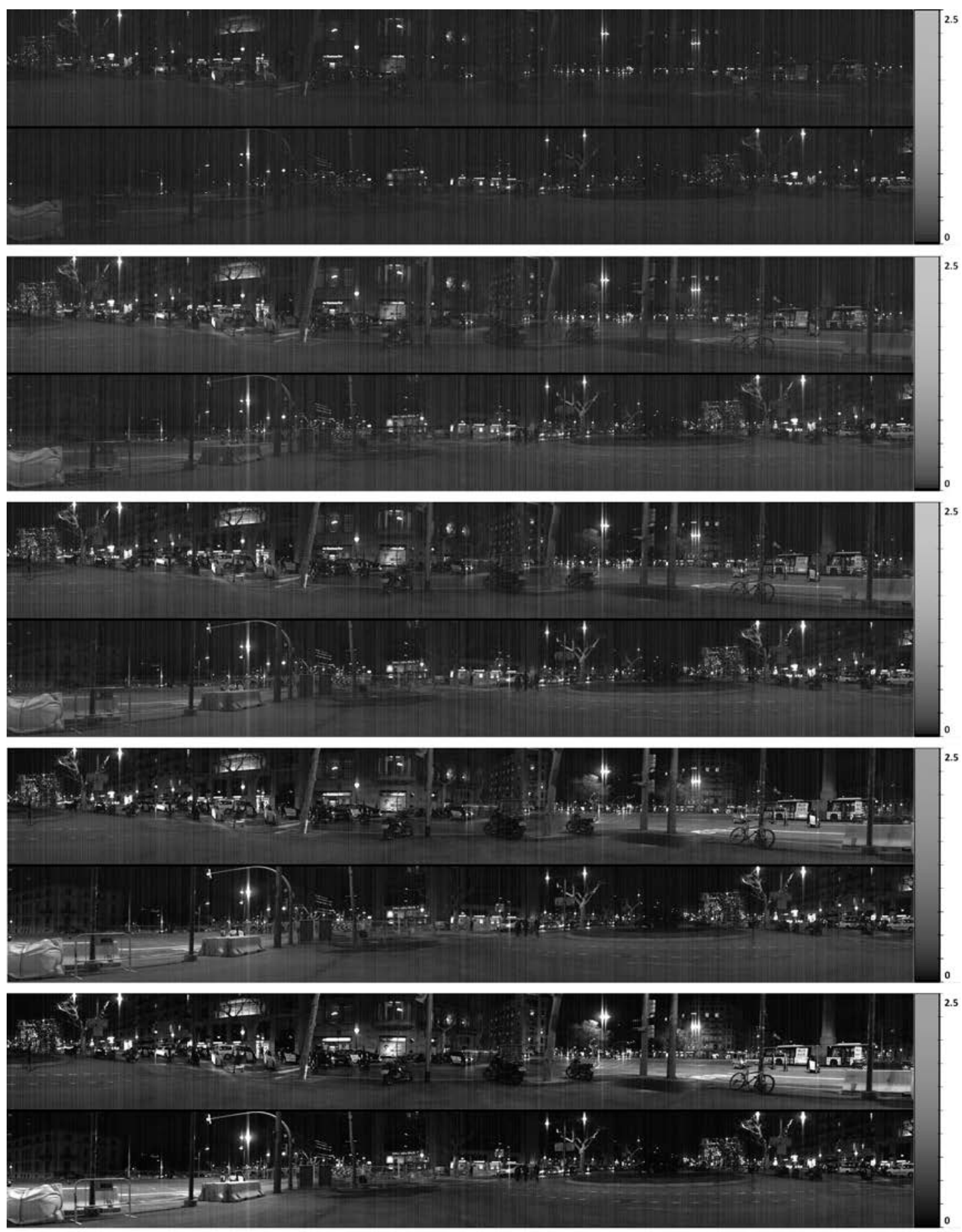

Fig. 11. (Top to bottom) The photoreceptoral urban nightscape in the cyanopic, melanopic, rhodopic, chloropic and erythropic spectral bands. The grayscale spans the range from 0 to 2.5 $\mathrm{Wm}^{-2} \mathrm{sr}^{-1}$. 


\section{Discussion}

The results presented in this work are affected by several limitations. One of them stems from the fact that the irradiances at vertical planes have been computed from radiance distributions with a vertical swath limited to about $40^{\circ}$ (i.e., $20^{\circ}$ above and below the horizontal) instead of the nominal $180^{\circ}$ angular span extending from zenith to nadir. While in fact these radiance data capture the essential features of the urban nightscape from the viewpoint of pedestrians gazing horizontally, and the influence of the peripheral light sources is attenuated by their progressively slanted incidence, a more precise evaluation of the vertical irradiances would require mapping the urban radiance for the entire hemisphere, either by means of successive scans at different heights above and below the horizon or by using an hyperspectral camera with an allsky hemispheric imaging lens and a rotating slit. On the other hand, while the radiant and photometric parameters of the urban flux can be easily determined with enough accuracy and precision, the outcomes related with the physiological influence of light at night are subject to greater uncertainties; this is due, however, to the still incomplete knowledge about these phenomena, and not to the hyperspectral device itself or the data reduction procedures implemented in this work.

As already mentioned in Section 2.1, the measurement campaign was held in a period of new Moon, with no moonlight present in the urban scenario. The contribution of moonlight depends on several factors, like the Moon phase, the EarthMoon distance, the altitude of the Moon over the horizon, and the local atmospheric conditions, including the aerosol concentration profile, the optical density of the atmosphere, and the type, structure, fraction of sky coverage and optical properties of clouds, among other. Typical estimates set at about $E_{m}=0.27 \mathrm{Ix}$ the maximum moonlight illuminance at ground level (Driggers et al., 2012). Assuming that the urban lansdcape surfaces have a Lambertian behaviour and a purposedly high average reflectance $\rho=30 \%$, this level of moonlight illuminance would translate into a nighstscape luminance $L_{m}=\rho E_{m} / \pi=0.026 \mathrm{~cd} / \mathrm{m}^{2}$. This value is considerably smaller than the average luminance recorded at the measurement site $\left(4.18 \mathrm{~cd} / \mathrm{m}^{2}\right)$. Even under the 
most favourable conditions, the moonlight is expected to have a relatively minor contribution to the overall urban nightscape luminance/illuminance, especially at the center of highly illuminated cities, due to the prevailing effects of the artificial light sources.

Artificial skyglow (Cinzano et al., 2001; Falchi et al., 2016) is an additional brightness source contributing to the urban spectral radiance, apart from the direct artificial lights and moonlight. Our field measurements include the effects of this additional source. Artificial skyglow in clear and moonless nights in widely populated urban areas may easily reach zenithal values in excess of $L_{s}=7.3 \times 10^{-3} \mathrm{~cd} / \mathrm{m}^{2}$ (Falchi et al., 2016). If this zenithal luminance level were kept constant across the $2 \pi$ upper hemisphere it would give rise to an incoming horizontal illuminance of order $E_{s}=\pi L_{s}=0.023 \mathrm{~lx}$, an order of magnitude below the full Moon expected value. Artificial skyglow tends to increase rapidly towards the horizon, so this estimate has to be taken as a lower bound. However, in overcast nights the reflection of artificial light on the base of the clouds may increase the artificial skyglow by factors in excess of 20 (Aubé, 2016; Bará, 2016), and, under the assumptions stated above, it would add $0.46 \mathrm{Ix}$ to the horizontal illuminances, almost doubling the expected maximum moonlight contribution.

These primary light sources, either artificial or natural in origin, are not the only ones that determine the spectral irradiance at the entrance of the observer's eyes. The illuminated reflecting surfaces present in the nightscape (buildings, vegetation, pavement, street furniture...), acting as extended secondary sources, also make their own distinctive contribution to forming the spectral irradiance at the entrance of the eye. Their spectral radiance in the direction of the observer cannot be deduced from the knowledge of the sources alone: if this radiance were to be calculated theoretically, it would require a detailed knowledge of the spatially-variant spectral bidirectional reflectance distribution function of all surfaces present in the nightscape (or, alternatively, making strong assumptions about their spectral reflectance and their approximate Lambertian angular behaviour). Using a hyperspectral camera it is possible to know the actual spectral radiance of all pixels of the image without the need of making these a priori assumptions. The contribution of the measured spectral 
radiance of the reflecting surfaces is already included in our calculations of the corneal irradiance and of the subsequent photoreceptoral inputs (see, e.g., Figs. 8, 9, 10).

Urban hyperspectral data also make possible to analyze the differential contribution of each particular patch of the scene to the final irradiance distribution, and could provide useful hints on the optical performance at nightime of the different materials and coatings used in architectural urban design. These complementary studies, however, were not attempted in this work.

The field of view of the individual pixels of the hyperspectral images is slightly larger than the field of view of the individual photoreceptors of the human eye. Although no attempt has been made in the designing step to matching these elementary fields, both are of same order of magnitude. The camera used in this work has an effective instantaneous field of view in the vertical direction of 4.4 arcmin, and the scan parameters provided a typical horizontal field of 3.1 arcmin. The nominal acuity of the human visual system for detail recognition tasks in foveal vision under photopic luminance conditions with naturally dilated pupils is conventionally taken as 1 arcmin. Note however that, from a radiometric viewpoint, there are two factors that contribute to enlarge the effective photoreceptoral field. One of them is the presence in all physiologically normal eyes of several kind of optical aberrations that contribute to enlarge the eye's optical point spread function to typical sizes of order several minutes of arc (Navarro et al, 1998). The other are the fixational intesaccadic movements of the eye that continuously shift the retinal image over several adjacent photoreceptors, and whose faster component $(40-100 \mathrm{~Hz})$, also kown as tremor, has typical amplitudes in the range of 1 minute of arc (Rucci and Poletti, 2015). Each individual foveal photoreceptor is then illuminated during its integration time by light coming from angular regions of the space slightly wider than what would be expected from the nominal visual acuity figure. The human perception of brightness in extended scenes, in turn, involves not only foveal but also peripheral vision, with characteristically larger photoreceptoral fields.

Ground-based hyperspectral images may provide relevant information for safety studies and for improving urban lighting design. As an anonymous reviewer correctly 
pointed out, the analysis of luminance (see section 4.1) may be useful for detecting regions of the urban nightscape that could be hardly perceived by people with night blindness (nyctalopia). The spectral information contained in the image hypercube could also be used to evaluate the visual appearance of the city for pedestrians and drivers with different conditions of color vision defficiency. These issues deserve further research work.

\section{Conclusions}

We described the use of a hyperspectral camera to characterize the urban emissions of light at night from a ground-based perspective, complementary to airborne or spaceborne remote sensing. Whereas the latter provide valuable data to estimate the amount of energy wasted skywards by public and private outdoor lighting systems, our present approach provides supplementary information from the city dwellers standpoint, allowing to assess other relevant aspects of the light pollution problem, as e.g. the presence of areas with light trespass or excessive source radiance, as well as to evaluate the visual shape of the urban nightscape and the inputs to the five retinal photoreceptors that provide photic time signals to the human circadian regulation system.

\section{Acknowledgments}

We acknowledge the useful suggestions and comments made by the anonymous reviewers of this manuscript.

\section{Funding}

This work has been developed within the framework of the Spanish Network for Light Pollution Studies (AYA2015-71542-REDT). 


\section{Conflicts of interests}

The Institut Cartogràfic i Geològic de Catalunya (ICGC) is a public body of the Catalonian Government that provides photometric and photogrammetric services to local communities, public administration bodies and private customers, including airborne and ground-based hyperspectral imaging.

\section{References}

Aasen, H., Burkart, A., Bolten, A., Bareth, G., 2015. Generating 3D hyperspectral information with lightweight UAV snapshot cameras for vegetation monitoring: From camera calibration to quality assurance. ISPRS Journal of Photogrammetry and Remote Sensing 108, 245-259. doi: /10.1016/j.isprsjprs.2015.08.002

Aubé, M., Kocifaj, M., Zamorano, J., Solano Lamphar, H.A., Sánchez de Miguel, A., 2016. The spectral amplification effect of clouds to the night sky radiance in Madrid. Journal of Quantitative Spectroscopy \& Radiative Transfer 181, 11-23.

Babey, S., Soffer, R., 1992. Radiometric Calibration of the Compact Airborne Spectographic Imager (CASI). Canadian Journal of Remote Sensing 18(4): 233-242.

Bará, S., 2013. Light pollution and solid-state lighting: reducing the carbon dioxide footprint is not enough. In: 8th Iberoamerican Optics Meeting and 11th Latin American Meeting on Optics, Lasers, and Applications, edited by Manuel Filipe P. C. Martins Costa, Proc. of SPIE Vol. 8785, 87852G, pp. 1-8. http://dx.doi.org/10.1117/12.2025344

Bará, S., 2014. Light pollution: Why should we care?. In: Second International Conference on Applications of Optics and Photonics, edited by Manuel Filipe P. C. Martins Costa, Rogério Nunes Nogueira, Proc. of SPIE Vol. 9286, 92862X, pp. 1-7. http://dx.doi.org/10.1117/12.2063547

Bará, S., 2016. Anthropogenic disruption of the night sky darkness in urban and rural areas. Royal Society Open Science 3: 160541 (2016). doi: 
http://dx.doi.org/10.1098/rsos.160541

Barducci, A., Marcoionni, P., Pippi, I., Poggesi, M., 2003. Effects of light pollution revealed during a nocturnal aerial survey by two hyperspectral imagers. Applied Optics 42 (21), 4349-4361.

Barducci, A., Marcoionni, P., Pippi, I., Poggesi, M., 2003. Light pollution observed by MIVIS and VIRS 200 during a nocturnal remote sensing campaign over Italy. In Remote Sensing for Environmental Monitoring, GIS Applications, and Geology II, Manfred Ehlers, Editor, Proceedings of SPIE Vol. 4886, pp. 29-38.

Barducci, A., Benvenuti, M., Bonora, L., Castagnoli, F., Guzzi, D., Marcoionni, P., Pippi, I., 2006. Hyperspectral remote sensing for light pollution monitoring. Annals of Geophysics 49 (1), 305-310.

Belward, A.S, Skøien, J.O., 2015. Who launched what, when and why; trends in global land-cover observation capacity from civilian earth observation satellites. ISPRS Journal of Photogrammetry and Remote Sensing 103, 115-128. http://dx.doi.org/10.1016/j.isprsjprs.2014.03.009

Bonmati-Carrion, M.A., Arguelles-Prieto, R., Martinez-Madrid, M.J., Reiter, R., Hardeland, R., Rol, M.A., Madrid, J.A., 2014. Protecting the melatonin rhythm through circadian healthy light exposure. International Journal of Molecular Sciences 15, 23448-23500.

Cai, H., 2013. Hygh dynamic range photogrammetry for synchronous luminance and geometry measurement, Lighting Research and Technology 45: 230-257. doi: $10.1177 / 1477153512453273$

Castiglione, L., Conticello, S.S., Esposito, M., Oldenhuis, R., Moon, S.G., Nicolai, A., Stoltz, S., Dettmann, J., 2012. The NightPod - An orbital motion compensation mechanism for ISS based imaging. In Proceedings of the 63rd IAC (International Astronautical Congress), Naples, Italy, Oct. 1-5, 2012, paper: IAC-12-B3.3.12

Chen, J., Dowman, I., Li, S., Li, Z., Madden, M., Mills, J., Paparoditis, N., Rottensteiner, F., Sester, M., Toth, C., Trinder, J., Heipke, C., 2016. Information from imagery: ISPRS scientific vision and research agenda. ISPRS Journal of Photogrammetry and Remote Sensing 115, 3-21. http://dx.doi.org/10.1016/j.isprsjprs.2015.09.008 
Cho, Y.M., Ryu, S-H., Lee, B.R., Kim, K.H., Lee, E., Choi, J., 2015. Effects of artificial light at night on human health: A literature review of observational and experimental studies applied to exposure assessment. Chronobiology International 32 (9), pp. 1294-1310. http://dx.doi.org/10.3109/07420528.2015.1073158

CIE, Commission Internationale de l'Éclairage, 1951. Proceedings Vol. 1, Sec 4; Vol 3, p. 37. Paris: Bureau Central de la CIE.

$\mathrm{CIE}$, Commission Internationale de l'Éclairage, 2010. Recommended system for mesopic photometry based on visual performance. Pub. CIE 191:2010.

CIE, Commission Internationale de l'Éclairage, 2015. CIE Publication TN 003:2015 Report on the First International Workshop on Circadian and Neurophysiological Photometry, 2013. Vienna : CIE.

Cinzano, P., Falchi, F., Elvidge, C.D., Baugh, K.E., 2000. The artificial night sky brightness mapped from DMSP satellite Operational Linescan System measurements. Mon. Not. R. Astron. Soc. 318, 641-657.

Cinzano, P., Falchi, F., Elvidge, C.D., 2001. The first World Atlas of the artificial night sky brightness. Mon. Not. R. Astron. Soc. 328, 689-707.

Cinzano, P., Elvidge, C.D., 2004. Night sky brightness at sites from DMSP-OLS satellite measurements. Mon. Not. R. Astron. Soc. 353, 1107-1116. doi:10.1111/j.13652966.2004.08132.x

Clark, M.L., Kilham, N.E., 2016. Mapping of land cover in northern California with simulated hyperspectral satellite imagery. ISPRS Journal of Photogrammetry and Remote Sensing 119, 228-245. http://dx.doi.org/10.1016/j.isprsjprs.2016.06.007

Corbera, J., Palà, V., Pérez-Aragüés, F., 2015. Mapping Nocturnal Light Pollution. GIMInternational., November 2015, 25-27.

Demarchi, L., Canters, F., Cariou, C., Licciardi, G., Chan, J.C.-W., 2014. Assessing the performance of two unsupervised dimensionality reduction techniques on hyperspectral APEX data for high resolution urban land-cover mapping. ISPRS Journal of Photogrammetry and Remote Sensing 87, 166-179. http://dx.doi.org/10.1016/j.isprsjprs.2013.10.012

Driggers, R.G., Friedman, M.H., Nichols, J.M., 2012. Introduction to Infrared and 
Electro-Optical Systems, Second Edition (London: Artech House). p. 137.

Elvidge, C.D., Keith, D.M., Tuttle, B.T., Baugh, K.E., 2010. Spectral Identification of Lighting Type and Character. Sensors 10, 3961-3988. doi:10.3390/s100403961

Elvidge, C.D., Baugh, K., Zhizhin, M., Hsu, F.C., 2013. Why VIIRS data are superior to DMSP for mapping nighttime lights. In Proceedings of the Asia-Pacific Advanced Network v. 35, pp. 62-69. ISSN 2227-3026. http://dx.doi.org/10.7125/APAN.35.7

Estrada-García, R., García-Gil, M., Acosta, L., Bará, S., Sanchez de Miguel, A., Zamorano, J., 2015. Statistical modelling and satellite monitoring of upward light from public lighting. Lighting Research and Technology, in press. Published online, 21 April 2015. http://dx.doi.org/10.1177/1477153515583181

Falchi, F., Cinzano, P., Elvidge, C.D., Keith, D.M., Haim A., 2011. Limiting the impact of light pollution on human health, environment and stellar visibility. Journal of Environmental Management, 92 (10), 2714-2722. doi: 10.1016/j.jenvman.2011.06.029.

Falchi, F., Cinzano, P., Duriscoe, D., Kyba, C.C.M., Elvidge, C.D., Baugh, K., Portnov, B.A., Rybnikova, N.A., Furgoni, R. 2016, The new world atlas of artificial night sky brightness. Sci. Adv. 2, e1600377. (doi: 10.1126/sciadv.1600377)

Gallaway, T., Olsen, R.N., Mitchell, D.M., 2010. The economics of global light pollution. $\begin{array}{llll}\text { Ecological } & \text { Economics } & 69 & \text { (3), }\end{array}$ http://dx.doi.org/10.1016/j.ecolecon.2009.10.003

Gaston, K.J., Bennie, J., Davies, T.W., Hopkins, J., 2013. The ecological impacts of nighttime light pollution: a mechanistic appraisal. Biological Reviews 88 (4), 912927. http://dx.doi.org/10.1111/brv.12036

Gaston, K.J., Visser M.E., Hölker F., 2015. The biological impacts of artificial light at night: The research challenge. Philos Trans R Soc Lond B Biol Sci. 370:20140133. http://dx.doi.org/10.1098/rstb.2014.0133

Haim, A., Zubidat, A.E., 2015. Artificial light at night: melatonin as a mediator between the environment and epigenome. Philos Trans $\mathrm{R}$ Soc Lond B Biol Sci. 370:20140121. http://dx.doi.org/10.1098/rstb.2014.0121

Hölker, F., Wolter, C., Perkin, E. K., Tockner, K., 2010. Light pollution as a biodiversity 
threat. Trends in Ecology and Evolution 25, 681-682.

Kotthaus, S., Smith, T.E.L., Wooster, M.J., Grimmond, C.S.B., 2014. Derivation of an urban materials spectral library through emittance and reflectance spectroscopy. ISPRS Journal of Photogrammetry and Remote Sensing 94, 194-212. http://dx.doi.org/10.1016/j.isprsjprs.2014.05.005

Kruse, F.A, Elvidge, C.D., 2011. Characterizing urban light sources using imaging spectrometry. In: Stilla U, Gamba P, Juergens C, Maktav D (Eds) JURSE 2011 - Joint Urban Remote Sensing Event, Munich, Germany, April 11-13, pp. 149-152.

Kyba, C.C.M, Hänel, A., Hölker, F., 2014. Redefining efficiency for outdoor lighting. $\begin{array}{lllll}\text { Energy and } & \text { Environmental }\end{array}$ http://dx.doi.org/10.1039/c4ee00566j

Lucas, R.J., Peirson, S.N., Berson, D.M., Brown, T.M., Cooper, H.M., Czeisler, C.A., Figueiro, M.G., Gamlin , P.D., Lockley, S.W., O’Hagan, H.B., Price, L.L.A., Provencio, I., Skene, D.J., Brainard, G.C., 2014. Measuring and using light in the melanopsin age. Trends in Neurosciences 37 (1), 1-9.

Mann, S., Picard, R.W., 1995. On being 'undigital' with digital cameras: extending dynamic range by combining differently exposed pictures, Proc. IS\&T's 46th annual conference, Washington DC, May 1995. pp. 422-428.

McCluney, W.R., 2014. Introduction to Radiometry and Photometry, 2nd ed (Norwood: Artech House). Equation (1-17), p. 16.

Miller, S.D., Straka, W., Mills, S.P., Elvidge, C.D., 2013. Illuminating the Capabilities of the Suomi National Polar-Orbiting Partnership (NPP) Visible Infrared Imaging Radiometer Suite (VIIRS) Day/Night Band. In: Remote Sensing, Vol.5, pp.67176766.

Navarro, R., Moreno, E., Dorronsoro, C., 1998. Monochromatic aberrations and pointspread functions of the human eye across the visual field. Journal of the Optical Society of America A 15: 2522-2529.

Pipia, L., Alamús, R., Tardà, A., Pérez, F., Palà, V., Corbera, J., 2014. A Methodology for Luminance Map Retrieval using Airborne Hyperspectral and Photogrammetric Data. In: Earth Resources and Environmental Remote Sensing/GIS Applications V, 
edited by Ulrich Michel, Karsten Schulz, Proc. of SPIE Vol. 9245, 924500, pp 1-12.

Rea, M.S., Figueiro, M.G., Bullough, J.D., Bierman, A., 2005. A model of phototransduction by the human circadian system. Brain Research Reviews 50, $213-228$.

Rea, M., Figueiro, M.G., Bierman, A., Bullough, J.D., 2010. Circadian light. Journal of Circadian Rhythms 8:2 pp. 1-10. http://dx.doi.org/10.1186/1740-3391-8-2.

Rea, M.S., Figueiro, M.G., Bierman, A., Hamner, R., 2012. Modeling the spectral sensitivity of the human circadian system. Lighting Research and Technology 44, 386-396. Corrigendum, 2012 : Lighting Research and Technology 44, 516.

Rucci, M., Poletti, M., 2015. Control and functions of fixational eye movements. Annual Review of Vision Science 1: 499-518. doi: 10.1146/annurev-vision-082114-035742

Sánchez de Miguel, A., Zamorano, J., Gómez-Castaño, J., Pascual, S., 2014. Evolution of the energy consumed by street lighting in Spain estimated with DMSP-OLS data. Journal of Quantitative Spectroscopy \& Radiative Transfer 139, 109-117. http://dx.doi.org/10.1016/j.jqsrt.2013.11.017

Schreuder, D., 2008. Outdoor Lighting: Physics, Vision and Perception. (Berlin: Springer) p. 88

Stevens, R.G., Brainard, G.C., Blask, D.E., Lockley, S.W., Motta, M.E., 2013. Adverse Health Effects of Nighttime Lighting. American Journal of Preventive Medicine 45 (3), pp. 343-346. http://dx.doi.org/10.1016/j.amepre.2013.04.011

Stockman, A., Jägle, H., Pirzer, M., Sharpe, L. T., 2008. The dependence of luminous efficiency on chromatic adaptation. Journal of Vision, 8(16):1, 1-26, http://journalofvision.org/8/16/1/, doi:10.1167/8.16.1.

Yang, F., Matsushita, B., Yang, W., Fukushima, T., 2014. Mapping the human footprint from satellite measurements in Japan. ISPRS Journal of Photogrammetry and Remote Sensing 88, 80-90. doi: http://dx.doi.org/10.1016/j.isprsjprs.2013.11.020 